\title{
INADVERTENT INCREASE IN INSPIRED OXYGEN CONCENTRATION DUE TO DEFECT IN VENTILATOR BELLOWS
}

\author{
John Longmuir and Douglas B. Craig
}

WE PREVIOUSLY REPORTED the manner in which a hidden defect in an oxygen failsafe device on an anaesthetic gas machine produced contamination of the nitrous oxide supply with oxygen proximal to the rotameter block. ${ }^{1}$ This resulted in the inadvertent administration of higher than intended inspired oxygen concentrations during anaesthesia. We encountered another example of accidental administration of inspired oxygen concentrations higher than intended, and traced the source of the excess oxygen to a small tear in the bellows of an anaesthetic ventilator. Since this tear did not alter the operation of the ventilator, the leakage of oxygen into the anaesthetic circuit from the driving gas was not immediately recognized.

During nitrous oxide/oxygen, narcotic and muscle relaxant anaesthesia for cholecystectomy in a healthy 20-year-old patient it became apparent that the depth of anaesthesia was less than expected. Ventilation was controlled using an oxygen driven Ohio model 300 anaesthesia ventilator, with a tidal volume of $800 \mathrm{ml}$ at a frequency of $9 / \mathrm{min}$. Gas flows of $5 \mathrm{lpm}$ nitrous oxide, $2 \mathrm{lpm}$ oxygen were used in a circle system. Analysis of the inspired oxygen concentration using a Beckman paramagnetic analyser revealed a concentration of 45 per cent, instead of the expected 28.5 per cent. Analysis following change to gas flows of $6 \mathrm{lpm}$ nitrous oxide, $2 \mathrm{lpm}$ oxygen revealed 40 per cent oxygen instead of the expected 25 per cent. At this point the surgical procedure was completed. Recovery was uneventful with no evidence of recall during anaesthesia.

The anaesthesia gas machine and ventilator were removed from service. Oxygen analysis at various rotameter settings without the ventilator in operation revealed appropriate oxygen concentrations. The added effect of the ventilator was examined as follows:

A test lung was attached to the circle system of the anaesthetic gas machine and ventilated with a tidal volume of $700 \mathrm{ml}$ at a rate of $12 / \mathrm{min}$. Peak circuit pressure was $20 \mathrm{~cm} \mathrm{H}_{2} \mathrm{O}$. The fresh gas added to the anaesthetic circuit was 100 per cent nitrous oxide while 100 per cent oxygen was used to power the ventilator. The nitrous oxide flow rate was varied from 1-10 lpm. In-circuit oxygen concentrations were measured after each flow change, without the ventilator, and then at five-minute intervals for 30 minutes following resumption of ventilator operation.

\section{Results ANd Discussion}

The oxygen concentration in the anaesthetic circuit was found to be 0 per cent after each change of nitrous oxide flow rate, without the ventilator in operation.

Department of Anaesthesia, Health Sciences Centre, and University of Manitoba, Winnipeg, Manitoba. 
The changes in oxygen concentration produced by the ventilator are summarized in the table. As there was no change in concentration after five minutes, only these data are presented.

TABLE I

\begin{tabular}{ccc}
\hline \hline Liters per minutes & \multicolumn{2}{c}{$\begin{array}{c}\text { Percentage of oxygen in } \\
\text { anaesthetic circuit }\end{array}$} \\
\cline { 3 - 4 } $\begin{array}{c}\mathrm{N}_{2} \text { O flow into } \\
\text { anaesthetic circuit }\end{array}$ & $\begin{array}{c}\text { Without } \\
\text { ventilator }\end{array}$ & $\begin{array}{c}\text { With } \\
\text { ventilator }\end{array}$ \\
\hline 1 & 0 & 55 \\
2 & 0 & 55 \\
3 & 0 & 46 \\
4 & 0 & 41 \\
5 & 0 & 38 \\
6 & 0 & 35 \\
7 & 0 & 30 \\
8 & 0 & 28 \\
9 & 0 & 28 \\
10 & 0 & 28 \\
\hline
\end{tabular}

Percentage of oxygen in Anaesthetic Circle System during 100 per cent nitrous oxide fresh gas inflow and test lung ventilation with oxygen driven ventilator. Samples with ventilator taken five minutes following change of nitrous oxide flows.

It is clear that oxygen leaked into the anaesthetic circuit during the use of the ventilator. The effect of this oxygen leak in reducing the in-circuit nitrous oxide concentration was dependent on the minute inflow of fresh gas, with maximum effects of lower flow rates. In clinical use, several factors in addition to fresh gas inflow rate would modify the net effect of oxygen leakage on the gas composition in the anaesthetic circuit. These include the type of circuit, composition of the fresh gas inflow, tidal volume, respiratory frequency, inspiratory flow rate, airway pressures and uptake of the various gases. Use of a gas other than oxygen to drive the ventilator would also have obvious effects.

The source of the oxygen leak was found to be a $1.2 \mathrm{~cm}$ linear tear in the upper flange of the bellows. This tear was large enough to allow the driving gas to leak into the interior of the bellows, but not large enough to affect the operation of the ventilator otherwise. Large defects normally become apparent when this type of ventilator fails to cycle.

The defective bellows had been in service for nine months, and was last tested and found intact one month prior to this incident.

This report should serve as another reminder to the anaesthetist that small and hidden defects in his equipment may produce clinically significant effects. In both this and our earlier report, investigation of unexplained light levels of anaesthesia led to surprising discoveries. In both instances, although the rotameters were functioning properly, patients received more oxygen, and less nitrous oxide, than the flow meters indicated. Routine continuous use of an in-circuit oxygen analyzer would have identified both problems at their beginning. In the future oxygen analyzers will likely become a mandatory component of all anaesthetic gas 
LONGMUIR \& CRAIG: INCREASED INSPIRED OXYGEN DUE TO VENTILATOR DEFECT 329

machines. Until that time, the best defence against defective apparatus will remain an element of curiosity and a high index of suspicion.

\section{RÉSUMÉ}

Une petite déchirure dans le pli du ballon d'un respirateur utilisé en anesthésie a été cause d'une anesthésie plus légère que prévue, ceci à cause d'une élévation de la $\mathrm{Fi}_{\mathrm{O}_{2}}$ du mélange protoxyde d'azote-oxygène.

\section{REFERENCE}

1. Chaig, D.B. \& Longmuir, J. An unusual failure of an oxygen fail-safe device. Can. Anaes. Soc. J. 18: 576 (1971). 